Western University

Scholarship@Western

Winter 3-24-2020

\title{
Older Adults and Information and Communication Technologies in the Global North
}

Molly-Gloria R. Harper

Western University

Barry Wellman

University of Toronto

Anabel Quan-Haase

The University of Western Ontario, aquan@uwo.ca

Follow this and additional works at: https://ir.lib.uwo.ca/fimspub

Part of the Communication Technology and New Media Commons, Gerontology Commons, Inequality and Stratification Commons, Library and Information Science Commons, Other Communication Commons, Social Media Commons, and the Social Psychology and Interaction Commons

Citation of this paper:

Harper, G. M., Wellman, B., \& Quan-Haase, A. (2020). ICTs and older adults in the Global North. In D. Danan Gu \& M. E. Dupre (Eds.), Encyclopedia of Gerontology and Population Aging. Berlin: Springer. 


\section{Older Adults and Information and Communication Technologies in the Global North}

Harper, G. M., Wellman, B., \& Quan-Haase, A. (2020). ICTs and older adults in the Global North. In D. Danan Gu \& M. E. Dupre (Eds.), Encyclopedia of Gerontology and Population Aging. Berlin: Springer.

\section{Overview}

At all ages, people are incorporating information and communication technologies (ICTs) into their lives. It is not that they have stopped talking with each other in-person, it is that ICTs complement their interactions when they cannot be together face-to-face. Since the 1990s, email has provided a routine way to stay in touch and sustain meaningful contact over distance. But not all age groups have adopted ICTs with the same enthusiasm. Research in the Global North has consistently reported that age plays an important role in ICT adoption and use (Anderson and Perrin 2017). For example, older adults have been the least likely to use ICTs, and even when they do use ICTs, they are less active in their use (Blank and Groselji 2014; Haight, Quan-Haase, and Corbett 2014; Schreurs, Quan-Haase, and Martin 2017). Yet, this is changing. As more older adults use ICTs, analysts are wondering how such ICTs affect older adults' social networks (Wang, Zhang and Wellman 2018; Wellman, Quan-Haase and Harper forthcoming): Are ICTs helping older adults build, maintain, or diminish personal networks? And how are they supporting or limiting the exchange of social support both for local and long-distance social networks? Moreover, are ICTs affecting different types of social ties differently — be they kin, friend, neighbor, workmate, or churchgoer; or strong or weak?

This is not just a shift in the means of communication, with one medium replacing another. In many situations, it is a fundamental shift in the structure of people's connections: from group-based interaction in a single, local, and solidary community to multiple, far-flung 
and loosely knit networks. Until the proliferation of automobiles and telephones, most peoples' communities consisted of a relatively small number of densely connected social ties, often organized around the home, workplace, and local activities with members sharing similar backgrounds and beliefs (Hampton and Wellman 2018). The post-World War II technological innovations of the telephone, the family car, and the internet facilitated and sustained contact beyond individuals' local, bounded groups. This has resulted in a shift toward "networked individualism" where individuals build and maintain their own personal networks using personal computers and mobile phones in conjunction with face-to-face encounters to weave together their distinct and personal social networks (Rainie and Wellman 2012, 2019; Wellman, et al. forthcoming).

\section{Deconstructing the "Grey Divide"}

Despite the augmented connectivity that ICTs provide, there are fears that the shift to a networked society can be alienating for older adults (Neves, Fonseca, Amaro and Pasqualotti 2018). Those older adults who lack digital literacy could experience a "grey divide" by being left behind in the transition to networked individualism (Quan-Haase, Wang, Wellman and Zhang 2018). The concept of the grey divide suggests that age-related factors hinder the ability of older adults to take advantage of ICTs. Investigations into the grey divide have examined older adults' involvement in ICTs, such as internet use (Friemel 2016), social networking sites (Haight et al. 2014), and microblogging (Blank 2017). However, these approaches often disregard differences in older adults' ICT use and assume that older adults commonly share beliefs, assumptions, and savviness (Quan-Haase, Williams et al. 2018). Yet, old age is never a static demographic. In addition to some older adults having started using ICTs in later life, longtime users of ICTs have 
grown up into older age (Anderson and Perrin 2017; Quan-Haase, Wang et al. 2018; Wang el. 2018).

Research has found only a loose association between older adults' skill levels, underlying orientations, and online engagement, with a variety of types of ICT users among older adults (Quan-Haase, Williams et al., 2018): i.e., the digital skills of older adults do not determine the extent to which they use ICTs. Some older adults scarcely do anything online while some are apprehensive but overcome their fears to do multiple activities. Many are happy with just using email and searches while others keep plunging into new activities. At the extremes, there are some non-users as well as some who put their lifetime panoply of ICT skills to good use. Thus, while skill level can limit what activities some older adults engage in online, there are older adults who do not let their skill levels get in the way.

\section{Integrating a Life-Course Approach}

A life-course approach helps understand how individuals in different life stages vary in their network structure as well as their patterns and understanding of media use (Hagestad and Neugarten 1985; Shanahan 2000; Wellman, Quan-Haase, and Harper 2019; Robinson et al. 2015; also see Life course Perspective in this volume). It also helps to understand how contextual and institutional factors influence the ways in which different age groups vary in their social networks and media use. Research shows that younger adults make more extensive and varied use of ICTs (Quan-Haase, Williams et al. 2018, Quan-Haase, Wang, et al. 2018; Anderson and Perrin 2017). However, this is not a stark dichotomy of young versus old. Rather, individuals in different age groups conserve media, sticking with what they first learned to use. Although most younger adults are comfortable using ICTs routinely in their lives, that many older adults are 
active online and use ICTs for a wide range of communication, information, and connectivity activities (Quan-Haase, Williams et al. 2018, Quan-Haase, Wang, et al., 2018).

\section{Key Research Findings}

Mainstream media's focus on the benefits and opportunities of ICTs pays scant regard to the unique challenges they present for older adults. The challenges are varied and often center around a lack of digital skills compared to younger adults and declining social networks with age, resulting in older adults less apt to being networked. Yet, many older adults are content with their current engagement with ICTs and do not feel a need to further integrate technologies into their lives. Rather, they value the time spent on other, non-ICT activities.

\section{Benefits}

ICTs are tools that increase geographical reach and frequency of contact because of their convenience, low cost, and relative ease of use. They have become routinely incorporated into the lives of older adults, allowing them to reach people more easily, stay in touch, meet new people, and increase the quality and quantity of communication with others (Quan-Haase et al. 2017). They have weakened, but not eliminated, the effects of distance on interpersonal networks (Mok, Wellman and Carrasco 2010), enabling older adults to enhance connectivity with groups and individuals regardless of location (Wang, Zhang and Wellman 2018).

1. Facilitating Interpersonal Contact: Research shows that ICTs have enabled older adults to remain engaged with diverse network members (Bromell and Cagney 2014; Cotten et al. 2013). Turning to ICTs garners a sense of being there and being connected even if in-person contact is not frequent. It aids aging adults in overcoming barriers to connectivity across distances or physical constraints due to the abundant support available online (Quan-Haase, Zhang, Wellman, and Wang 2019). A good part of the allure of ICTs for older adults is their 
ability to transcend distance, thus increasing connectivity and maintaining connections with kin, especially when they are not able to see them in-person frequently (Mok et al. 2010).

Strengthening such long-distance ties is particularly relevant for those feeling lonely (Dickens, Richards, Greaves, and Campbell 2011). In doing so, older adults can mitigate such loneliness by being able to enjoy special events and moments in the lives of their loved ones, such as watching grandchildren grow up.

By keeping up with kin and friends, older adults are also able to learn, reconnect with old acquaintances, and grow their networks with new relationships (Quan-Haase et al. 2019). For example, older adults especially rely on email, supplementing email communication with Facebook, and video chat applications such as Skype and FaceTime for communication with their friends and relatives near and far (Quan-Haase et al. 2019).

2. Social Support: Older adults use ICTs to complement in-person and telephone contact, relying on it for companionship, maintaining latent ties, coordinating meet-ups, and getting advice (Rios, Wohn, and Lee 2019; Quan-Haase, Mo, and Wellman 2017). Contradictory to fears that ICTs are inadequate for meaningful contact (Hampton and Wellman 2018), older adults use ICTs to provide a variety of support, including companionship, emotional aid, services, and information. Moreover, ICTs have fostered older adults' awareness of needs, feelings of reliance that support is available, and the delivery of help. They have less fear that isolation will mean that they--and their loved ones--will be unable to deal with social isolation, loneliness, and emergencies (Cotten et al. 2013; Dickens et al. 2011; Cornwell and Waite 2009).

Older adults' desire to learn how to use ICTs has become a form of social support in itself. For example, as ICTs expand in scope and demand constant updates, older adults often 
reach out to peers and younger family members for aid in dealing with ICTs, especially help with applications such as social networking sites and video chatting (Quan-Haase et al. 2017).

3. Positive Outcomes and Increased Well-Being: The affordances offered by ICTs may bolster older adults' feelings that they continue to matter and that others acknowledge and appreciate them (Francis, Rikard, Cotten, and Kadylak 2017). Having digital devices available 24/7 and being able to reach out, especially when help is needed, offers older adults more mental freedom and feelings of belonging (Quan-Haase et al. 2019). Furthermore, ICTs allow older adults to remain in control where they can engage in efforts to prevent their social networks from declining despite possible physical limitations. They may be especially important for those who have limited capacity to visit their friends and relatives in person, thereby lessening their feelings of isolation and loneliness. Possibly because of more time available after retirement and more involvement in voluntary groups (Brokaw, 1998; Putnam, 2000), older adults use ICTs to coordinate their group involvement (Quan-Haase, Wellman, and Harper 2019). ICTs such as email, text messaging, and some social media like Facebook facilitate coordinating events, sending monthly newsletters, and exchanging information and support.

\section{Challenges}

1. Digital Skill Level: As many older adults began using ICTs later in life, they may have limited digital skills and activities (Hargittai and Dobransky 2017; Zimmer 1999). Fear and skepticism toward technology can be coupled with privacy concerns (Elueze and Quan-Haase 2018) and difficulties in learning (Yuan, Hussain, Hales, and Cotten 2016). Yet, some older adults feel they have little choice in adopting ICTs and learning how to use them because of pressure and encouragement from peers and younger family and friends (Quan-Haase, Martin and Schreurs 2016). 
2. Declining Social Networks: The family and friends of older adults are more apt to become frail, disconnected, and die, thereby reducing the number of available ties. Older adults sometimes move from houses to apartments, disconnecting existing neighboring ties but making available potential new ties. Because of the vital role community plays in overall health, shrinking network size becomes a concern when older adults relocate or move into retirement homes or care facilities (Wu, Prina, Barnes, Matthews, and Brayne, 2015; Weeks, Keefe, and MacDonald, 2012; Roy, Dube, Despres, Freitas, and Legare, 2018). Members of older adults' social networks, particularly family members, can live further away, resulting in less frequent and limited face-to-face communication. As a result, older adults are more likely to have feelings of social isolation, which presents concerns over their physical, mental, and social well-being (Cornwell and Waite 2009; Cotten, Anderson, and McCullough 2013; Holt-Lunstad, Smith, Baker, Harris and Stephenson 2015). Smaller older adults' support networks may affect a poorer overall quality of life due to the increased stress of feeling alone and decreased self-confidence (Bahramnezhad, Chalik, Bastani, Taherpour, and Navab 2017). ICTs allow older adults to be proactive in overcoming challenges of shrinking social networks and geographical barriers because they are able to reconnect with old friends, make new connections, learn and interact with younger generations, and participate in and/or see life's special moments (Quan-Haase, Zhang, Wellman, and Wang 2018; Madden 2010; Selywn, 2004; Peek et al., 2016). Moreover, ICTs allows older adults to maintain their strong and weak ties across distance, filling in-person communication gaps.

3. Evaluating Networked Individualism: Not everyone living in a networked society is a networked individual, even with pervasive technologies helping them to stay connected anywhere, anytime (Hampton 2016). Some networked individuals have a diverse variety of roles 
within larger networks and used more communication channels to connect with friends and relatives. With sizable social networks, they have embraced ICTs. They are open minded about making new connections to expand their networks and maintaining both personal and professional ties. By contrast, although socially bounded individuals have many social ties and appreciated ICTs, they use them within a small set of groups, socializing with the same people for different activities — usually kin and neighbors. Finally, some socially limited individuals have smaller networks, rarely participate in groups, are limited in their use of ICTs, and are hesitant to adopt newer technologies (Wellman et al. 2019). One study reports that older adults less apt to be networked individuals or socially bounded than to be socially limited (Wang et al. 2018).

\section{Future Directions for Research}

It is time that the myth fades away that older adults are languishing at home without the benefits of ICTs to stay connected. As older adults are not a homogenous group, public policy needs to take into consideration the wide range of variability present among older adults. It is critical to develop tools and applications that specifically support this age group, their current activities and goals rather than pushing tools at them that are not linked to their everyday practices.

A starting point is the need for digital skills training for older adults to take their level of digital skill into account as well as motivation when designing the course. Because digital skills vary considerably, placing older adults into groups solely on the basis of their age makes learning difficult (Quan-Haase, Williams et al. 2018). Rather, taking current digital skill level into account would allow training sessions to be personalized based on digital skills, confidence, and needs (Quan-Haase, Wellman, and Zhang forthcoming). Having savvy older adult users take 
on leadership roles as mentors for other older adults (Quan-Haase, Williams et al. 2018) would allow digital skills to be taught in peer-to-peer settings, lowering anxiety levels.

In developing applications for older adults, the question of more limited use of ICTs remains salient. Is this limited use a short-term cohort effect of older adults not being ICT-adept because they did not use ICTs when they were younger or will it remain a longstanding situation of old age? If it is a short-term cohort effect, then it is a pressing problem for now, but not for the future. If it is a long-term effect of old age, then design issues need to be addressed. that could allow older adults to make greater use of ICTs. For example, many older adults have difficulty with smartphones' small screens, small keys, and jargon-filled applications. The growing literature on design requirements could be translated into a combination of software and hardware (Chen 2016; Neves et al. 2017).

Policy development rests in part on the removal of the negative connotations surrounding older adults' ICT use. Rather than being uninterested, many older adults recognize the utility of online communication and are eager to learn, making it important to offer such opportunities that meet these needs. Policy approaches should emphasize that older adults' online activities can be gratifying and manageable and not just a hobby or entertainment. Integrating ICTs into older adults' lives should have positive benefits for well-being including lower levels of loneliness, strengthening social relationships (Cotten, Anderson, and McCullough 2013), providing relevant information, making arrangements, shopping, and developing more confident narratives of digital mastery (Quan-Haase, Williams et al. 2018; Neves et al. 2018; Quan-Haase et al. 2016).

\section{Summary}

Older adults are not born old; they grow into it. Those aged $65+$ often recognize that the phase of becoming "old" is as much a socially determined birthday number as it is an actual signifier of a 
life change. After decades of lower ICT adoption than younger generations, older adults are now flocking to use them (Anderson and Perrin 2017). Just as for other age groups, once older adults start to use ICTs, they incorporate these technologies into their everyday lives for communication and information. They engage in a variety of activities according to the kinds of networks they are involved in, their digital skill level, and their comfort with these technologies (Quan-Haase, Williams et al. 2018). Older adults who use ICTs have the potential to link lives within and across generations over a lifetime. Feelings of strong and weak bonds with family and friends drive digital connectivity (Quan-Haase et al. 2017), both for those who are in multiple networks and for those who continue to be bounded in a few groups.

\section{Acknowledgement}

We are grateful for the financial support of the Social Science and Humanities Research Council of Canada (SSHRC). We are grateful to those who have advised and abetted us, especially Christian Beermann, Brent Berry, Isioma Elueze, Maria Kicevski, Christine Armstrong Mair, Helen Hua Wang, and Renwen Alice Zhang as well as those who transcribed the interviews. Most of all, we owe immense gratitude to the participants we studied who welcomed us into their homes.

\section{References}

Anderson M, Perrin A (2017) Tech adoption climbs among older adults. Washington: Pew Internet and American Life Project. http://www.pewinternet.org/2017/05/17/tech-adoptionclimbs-among-older-adults/. Accessed 19 August 2018 
Bahramnezhad F, Chalik R, Bastani F, Taherpour M, Navab E (2010) The social network among the elderly and its relationship with quality of life. Electron Physician, 9(11):4306-4311. https://doi.org/10.19082/4306

Blank G, Groselji D (2014) Dimensions of internet use, Information, Communication, \& Society 17(4):417-435. https://doi.org/10.1080/1369118X.2014.889189

Blank G (2017) The digital divide among Twitter users and its implications for social research, Social Science Computer Review 35(6):679-697. https://doi.org/10.1177/8094439316671698

Brokaw T (1998) The greatest generation. New York: Random House.

Bromell L, Cagney KA (2014) Companionship in the neighborhood context, Research on Aging 36(2):228-243. https://doi.org/10.1177/0164027512475096

Chen M (2016) How to make money in telehealth. Telehealth and Medicine Today 1(3). https://doi.org/10.30953/tmt.v1.83

Cornwell EY, Waite LJ (2009) Social disconnectedness, perceived isolation, and health among older adults, Journal of Health and Social Behavior 50(1):31-48. https://doi.org/10.1177/002214650905000103

Cotten SR, Anderson WA, McCullough BM (2013) Impact of internet use on loneliness and contact with others among older adults, Journal of Medical Internet Research 15(2):e39. https://doi.org/10.2196/jmir.2306

Dickens A, Richards S, Greaves C, Campbell J (2011) Interventions targeting social isolation in older people, BMC Public Health 11(1):647. https://doi.org/10.1186/1471-2458-11-647 
Elueze I, Quan-Haase A (2018) Privacy attitudes and concerns in the digital lives of older adults, American Behavioral Scientist 62(10):1372-1391. https://doi.org/10.1177/0002764218787026

Francis J, Rikard RV, Cotten SR, Kadylak T (2017) Does ICT use matter? Information, Communication \& Society 21. https://doi.org/10.1080/1369118X.2017.1417459

Friemel T (2016) The digital divide has grown old, New Media \& Society 18(2):313-331. https://doi.org/10.1177/1461444814538648

Hagestad GO, Neugarten BL (1985) Aging and the life course. In: Shanas E, Binstock R (eds) Handbook of aging and the social sciences, 2nd edn. Von Nostrand and Remold, New York, p 36-61

Haight M, Quan-Haase A, Corbett B (2014) Revisiting the digital divide in Canada, Information, Communication, \& Society 17(4):503-519. https://doi.org/10.1080/1369118X.2014.891633

Hampton KN (2016) Persistent and Pervasive Community, American Behavioral Scientist 60(1):101-124. https://doi.org/10.1177/0002764215601714

Hampton K, Wellman B (2018). Lost and Saved... Again: The Moral Panic about the Loss of Community Takes Hold of Social Media. Contemporary Sociology 47(6):643-651. https://doi.org/10.1177/0094306118805415

Hargittai E, Dobransky K (2017) Old dogs, new clicks, Canadian Journal of Communication 42(2):196-212. https://doi.org/10.22230/cjc.2017v42n2a3176

Holt-Lunstad J, Smith TB, Baker M, Harris T, Stephenson D )2015) Loneliness and social isolation as risk factors for mortality, Perspectives on Psychological Science, 10(2):227237. https://doi.org/10.1177/1745691614568352 
Madden M (2010) Older adults and social media. Washington: Pew Research Center. https://www.pewinternet.org/2010/08/27/older-adults-and-social-media/. Accessed 19 August 2018

Mok D, Wellman B, Carrasco JA (2010) Does distance matter in the age of the Internet? Urban Studies 47(13):2747-2783. https://doi.org/10.1177/0042098010377363

Neves BB, Franz RL, Munteanu C, Baecker R (2017). Adoption and feasibility of a communication app to enhance social connectedness amongst frail institutionalized oldest old: an embedded case study, Information, Communication \& Society, 20. https://doi.org/10.1080/1369118X.2017.1348534

Neves BB, Fonseca J, Amaro F, Pasqualotti A (2018) Social capital and Internet use in an agecomparative perspective with a focus on later life, PLoS ONE 13(2):e0192119. https://doi.org/10.1371/journal.pone.0192119

Peek S, Luijkx KG, Rijnaard MD, Nieboer ME, van der Voort CS, Aarts S, van Hoof J, Vrijhoef H, Wouters E (2016) Older adults' reasons for using technology while aging in place, Gerontology 62:226-237. https://doi.org/10.1159/000430949

Quan-Haase A, Wellman B, Zhang R (Forthcoming) Digital inequality among older adults, In: Hargittai E (ed) The Handbook of Digital Inequality. Edward Elgar, London

Quan-Haase A, Martin K, Schreurs K (2016) Interviews with digital seniors, Information, Communication \& Society 19(5):691-707. https://doi.org/10.1080/1369118X.2016.1140217

Quan-Haase A, Mo GY, Wellman B (2017) Connected seniors, Information, Communication \& Society 20(7):967-998. https://doi.org/10.1080/1369118X.2017.1305428 
Quan-Haase A, Williams C, Kicevski M, Elueze I, Wellman B (2018) Dividing the grey divide, American Behavioral Scientist 62(9):1207-1228. https://doi.org/10.1177/0002764218777572

Quan-Haase A, Wang H, Wellman B, Zhang A (2018) Weaving family connections on and offline. In: Neves BB, Casimiro C (eds) Connecting families. Bristol, England: Policy Press, p 57-77

Quan-Haase A, Zhang R, Wellman B, Wang H (2019) How older adults network via digital media. In: Graham M, Dutton WH (eds) Society and the Internet, 2nd edn. Oxford University Press, Oxford, p 96-108

Rainie L, Wellman B (2012) Networked. MIT Press, Cambridge, MA

Rainie L, Wellman B (2019) The triple revolution in everyday life. In: Graham M, Dutton WH (eds) Society and the Internet, 2nd edn. Oxford University Press, Oxford, p 27-42

Robinson L, Cotten SR, Ono H, Quan-Haase A, Mesch G, Chen W... Stern MJ (2015) Digital inequalities and why they matter, Information, Communication \& Society 18(5):569-582. https://doi.org/10.1080/1369118X.2015.1012532

Rios, J, Wohn DY, Lee YH (2019) Effect of Internet literacy in understanding older adults' social capital and expected Internet support, Communication Research Reports. https://doi.org/10.1080/08824096.2019.1586664

Roy N, Dube R, Despres C, Freitas A, Legare F (2018) Choosing between staying at home or moving, PLoS One 13(1):e0189266. https://doi.org/10.1371/journal.pone.0189266

Schreurs K, Quan-Haase A, Martin K (2017) Problematizing the digital literacy paradox in the context of older adults' ICT use, Canadian Journal of Communication 42(2). https://doi.org/10.22230/cjc.2017v42n2a3130 
Shanahan MJ (2000) Pathways to adulthood in changing societies, Annual Review of Sociology 26:667-692. https://doi.org/10.1146/annurev.soc.26.1.667

Selwyn N (2004) The information aged, Journal of Aging Studies 18:369-384. https://doi.org/10.1016/j.jagin.2004.06.008

Wang H, Zhang R, Wellman B (2018) Are older adults networked individuals? Information, Communication \& Society 21(5):681-696. https://doi.org/10.1080/1369118X.2018.1428659

Weeks LE, Keefe J, MacDonald DJ (2012) Factors predicting relocation among older adults, Journal of Housing for the Elderly 26:355-371. https://doi.org/10.1080/02763893.2011.653099

Wellman B, Quan-Haase A, Harper MG (2019) The networked question in the digital age, Network Science (forthcoming)

Wu YT, Prina AM, Barnes LE, Matthews FE, Brayne C (2015) Relocation at older age, Journal of Public Health 37(3):480-497. https://doi.org/10.1093/pubmed/fdv050

Yuan S, Hussain SA, Hales KD, Cotten SR (2016) What do they like? Communication preferences and patterns of older adults in the United States, Educational Gerontology 42(3):163-174. https://doi.org/10.1080/03601277.2015.1083392 